\title{
Electroejaculation, semen characteristics and serum testosterone concentrations of free-ranging African elephants (Loxodonta africana)
}

\author{
JoGayle Howard, M. Bush, V. de Vos* and D. E. Wildt
}

National Zoological Park, Department of Animal Health, Smithsonian Institution, Washington, D.C. 20008, U.S.A. and * Kruger National Park, Republic of South Africa

\begin{abstract}
Summary. A regimented electroejaculation protocol (120 electrical stimulations; $10-$ $30 \mathrm{~V}$ ) was used to collect semen and characterize ejaculate quality from 9 adult, freeranging African elephants under anaesthesia. Eight of the 9 ejaculates contained high concentrations of progressively motile spermatozoa. The overall mean ejaculate volume, sperm concentration/ml ejaculate, sperm motility, sperm status and ejaculate $\mathrm{pH}$ were $93.3 \mathrm{ml}, 2408.6 \times 10^{6}$ spermatozoa $/ \mathrm{ml}, 70 \%, 3.9$ and $7 \cdot 4$, respectively. A high percentage (mean $77.5 \%$ ) of spermatozoa within each ejaculate was morphologically normal. Of the aberrant spermatozoa, $72 \%$ had a cytoplasmic droplet defect. When sperm viability was tested in vitro at $37^{\circ} \mathrm{C}$, sperm motility rating declined by at least half of the initial assessment within $3.5 \mathrm{~h}$ of semen collection. Generally, spermatozoa maintained motility in vitro for $<6 \mathrm{~h}$. Serum testosterone ranged from 1.4 to $8.2 \mathrm{ng} / \mathrm{ml}$ in 4 males evaluated in the morning $(07: 30-08: 00 \mathrm{~h})$. In 4 of the 5 bulls assessed in the afternoon $(15: 00-18: 00 \mathrm{~h})$, testosterone levels were $<0.9 \mathrm{ng} / \mathrm{ml}$. The remaining bull, evaluated at 16:00 h, had exceptionally high testosterone concentrations (peak 25.6 $\mathrm{ng} / \mathrm{ml}$ ) and a preputial discharge potentially indicative of 'musth'. The present study demonstrates that high quality semen can be collected consistently from the African elephant and that striking differences exist in serum testosterone amongst free-ranging males which may be due, in part, to a diurnal rhythm.
\end{abstract}

\section{Introduction}

A limited number of bull elephants exist in zoological collections because few zoos have suitable facilities for maintaining mature males. There are also considerable hazards involved in handling and managing adult bulls because of their occasional aggressive behaviour or unpredictable temperament. Artificial insemination could provide a mechanism to eliminate the need to maintain proven sires and introduce new genetic material from wild populations.

Spermatozoa have been collected from the excurrent testicular duct system of African elephants post mortem to study the effects of various diluents on the induction and maintenance of cellular motility (Jones, 1973, 1978; Jones, Rowlands \& Skinner, 1974; Jones, Bailey \& Skinner, 1975). Histological and biochemical features of the male reproductive tract have also been described using post-mortem tissue from elephants culled to avoid over-population (Johnson \& Buss, 1967a; Short, Mann \& Hay, 1967; Holt, Jones \& Skinner, 1980; Jones, 1980; Jones \& Brosnan, 1981). Less emphasis has been placed on establishing reproductive traits of live bull elephants because of inherent difficulties associated with handling, anaesthesia and animal availability.

Few attempts have been made to electroejaculate elephants and these often have been only partly successful. Jones (1973) reported collecting a spermic ejaculate on 1 of 2 attempted occasions from anaesthetized bulls. Ruedi \& Kupfer (1981) electroejaculated 3 males, 2 of which produced 
azoospermic or athenospermic ejaculates. Ruedi, Kupfer, Girard \& Gutzwiller (1983) electroejaculated 3 African elephants but obtained motile spermatozoa from only one bull. Therefore, efforts to determine baseline ejaculate traits of elephants have been hindered primarily by the lack of satisfactory and consistent semen collection procedures.

The objectives of the present study were to (1) examine the efficacy of a standardized electroejaculation method for collecting semen from free-ranging African elephants, (2) establish ejaculate traits and sperm characteristics and (3) assess testosterone concentrations during the electroejaculation procedure.

\section{Materials and Methods}

Electroejaculation. Nine adult bull elephants free-ranging in the $20000 \mathrm{~km}^{2}$ Kruger National Park, Republic of South Africa, were studied in August and September 1982. Males were lone bachelors or associated with 1 or 2 other bachelor males. Four of the males were evaluated in the morning beginning between $07: 30$ and $08: 00 \mathrm{~h}$ and the remaining bulls were assessed in the afternoon beginning between 15:00 and 18:00 h. Each elephant was immobilized for semen collection by dart injection with $10 \mathrm{mg}$ etorphine hydrochloride (M99: Reckitt \& Coleman, Hull, U.K.) i.m. This dosage generally induced a surgical plane of anaesthesia in lateral recumbency within 15 min of administration. The temporal glands of each male were examined for evidence of fluid secretion. Electroejaculation was performed using general methods previously described (Howard, Pursel, Wildt \& Bush, 1981; Howard, Wildt, Chakraborty \& Bush, 1983; Wildt et al., 1983). Faeces were manually removed from the rectum to ensure adequate contact between the rectal mucosa and ejaculatory probe. A Teflon rectal probe (diam. $9 \mathrm{~cm}$; length $77 \mathrm{~cm}$ : P-T Electronics, College Station, TX) (Text-fig. 1) containing 3 longitudinal, stainless-steel electrodes (width $1 \cdot 1 \mathrm{~cm}$; length $13.8 \mathrm{~cm} ; 7.5 \mathrm{~cm}$ from probe tip) spaced $3 \mathrm{~cm}$ apart was lubricated and inserted approximately $60 \mathrm{~cm}$ into the rectum. The probe was positioned so that the electrodes were orientated ventrally and ventral pressure was applied to the probe handle during stimulation. An AC $60 \mathrm{~Hz}$ sine-wave electroejaculator (P-T Electronics) was powered by a portable petrol-operated generator. A regimented electroejaculation sequence consisting of a total of 120 stimuli given in 3 series was administered. Each series of 40 stimuli was divided into 2 sets of 20 stimuli at 10 and $20 \mathrm{~V}$ (Series 1 ), 20 and $25 \mathrm{~V}$ (Series 2) and 25 and $30 \mathrm{~V}$ (Series 3), respectively. A rest period of 3-5 min was permitted between each series. The electrical stimuli were given in a 3-sec-on and 3-sec-off pattern, with a continuous rise in voltage from $0 \mathrm{~V}$ to the desired peak, then returning to 0 . The penis prolapsed from the prepuce during electrical stimulation and the ejaculate was collected in a warmed plastic container. Upon completing the electroejaculation protocol, 20-25 mg diprenorphine hydrochloride (Revivon: Reckitt \& Coleman) was administered i.v. to reverse the anaesthesia. Each male resumed a standing position within 2-4 min of drug injection.

Semen evaluation. Semen was evaluated in the field immediately after collection for ejaculate volume and $\mathrm{pH}$. Raw, undiluted aliquants were assessed microscopically at $37^{\circ} \mathrm{C}$ for sperm motility and status (forward progression). At least 8 separate fields at $\times 400$ magnification were each examined by 2 individuals, the average rating was calculated and rounded to the nearest whole percentage. Sperm status was a subjective estimate of the type of forward movement of the sperm cell using the following scale: 0 , no movement; 1 , slight side-to-side movement, no forward progression; 2, some side-to-side movement, occasional forward progression, usually in spurts; 3 , side-to-side movement, slow and steady forward progression; 4, steady, moderate forward progression; 5, steady, rapid forward progression. Sperm concentration was determined using standard haemocytometer methods (Wildt et al., 1983) and calculations were made of sperm number $/ \mathrm{ml}$ ejaculate and total sperm number/ejaculate. An aliquant from each ejaculate was fixed in $1 \%$ glutaraldehyde for subsequent evaluation of sperm morphology. Phase-contrast microscopy $(\times 1000)$ was used to assess 300 spermatozoa/ejaculate for the incidence of pleiomorphic forms. 


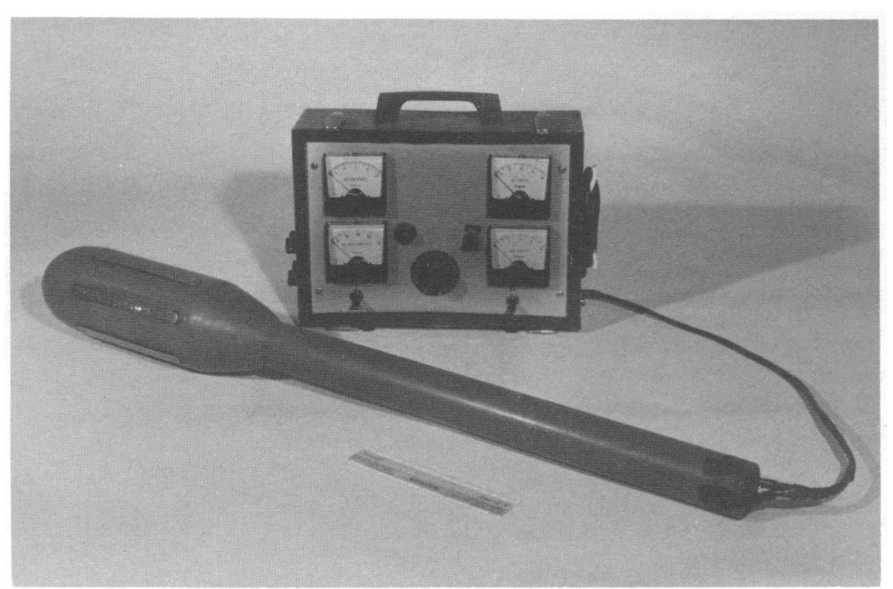

Text-fig. 1. Electroejaculator $(\mathrm{AC}, 60 \mathrm{~Hz}$ ) and rectal ejaculatory probe containing 3 longitudinal, stainless-steel electrodes used for semen collection from African elephants.

Raw aliquants from 6 ejaculates were used to determine duration of sperm viability in vitro at $37^{\circ} \mathrm{C}$. Sperm motility and status ratings were made microscopically at 30 -min intervals for up to $6 \mathrm{~h}$ or until $0 \%$ motility and 0 status were observed.

Testosterone evaluation. After the induction of anaesthesia in each male, serial blood samples were obtained immediately before the start of electroejaculation, immediately after each of the 3 electroejaculation series and then at 15 -min intervals for up to $45 \mathrm{~min}$ after the last stimulation. The mean intervals were $18 \mathrm{~min}$ from before electroejaculation to the end of Series 1, $8 \mathrm{~min}$ from the end of Series 1 to the end of Series 2, and $10 \mathrm{~min}$ from the end of Series 2 to the end of Series 3. The collected serum samples were stored at $-20^{\circ} \mathrm{C}$ until assayed in duplicate using a commercially available ${ }^{125}$ I-labelled testosterone radioimmunoassay (RSL NOSOLVEX: Radioassay Systems Laboratories, Inc., Carson, CA). The first and second antibodies were rabbit anti-testosterone-19carboxymethyl-ether-BSA and goat anti-rabbit gamma globulin, respectively. The crossreactivities of the first antibody had been previously determined as $100 \%$ with testosterone, $10 \cdot 3 \%$ with $5 \alpha$-dihydrotestosterone, and $<1 \%$ with $5 \beta$-dihydrotestosterone, $6 \beta$-hydroxytestosterone, androstenedione, androsterone, androstanedione, oestrone, oestradiol-17 $\beta$, oestriol, progesterone and corticosterone. Standard solutions of testosterone ranged from 0.005 to $0.5 \mathrm{ng} /$ tube. An aliquant $(50 \mu \mathrm{l})$ of each serum sample was added to $0.1 \mathrm{ml}$ of a testosterone-binding globulin inhibitor solution. Tracer $(0.5 \mathrm{ml})$ and first antibody $(0.5 \mathrm{ml})$ were added to all sample tubes, vortexed and incubated at $37^{\circ} \mathrm{C}$ for $120 \mathrm{~min}$. The precipitating antibody was then added and after mixing and incubation at $37^{\circ} \mathrm{C}$ for $60 \mathrm{~min}$, each sample was centrifuged, the supernatant decanted and the precipitate analysed for gamma emission. Inter- and intra-assay coefficients of variation were $10.9 \%(n=3)$ and $9.6 \%(n=6)$ and the minimum detectable assay sensitivity was 0.01 ng/tube.

Statistics. Values reported are means \pm s.e.m. Student's $t$ tests were used to assess significance of differences between means and $\chi^{2}$ analysis to evaluate differences in population distribution (Steel \& Torrie, 1960).

\section{Electroejaculation}

\section{Results}

Seminal fluid was collected from each of the 9 elephants and spermatozoa were detected in the ejaculate of 8 males. Initially, approximately 5-10 electrical stimuli were necessary to prolapse the 
penis completely from preputial sheath. Penile erection and engorgement of the corpora cavernosa were observed during stimulation of each animal. A dorso-ventral flexion of the tip of the penis occurred occasionally and could be initiated or prevented by varying the position of the rectal probe. Extension of the hind limbs was observed during electroejaculation due to stimulation of somatic motor nerves and musculature. During the times between the collection series, the penis became flaccid and retracted back into the prepuce. After completing electroejaculation and administering the anaesthetic antidote, elephants frequently urinated immediately after standing. Temporal gland secretion was observed in 3 bulls, with one demonstrating pronounced secretion at the time of electroejaculation. The latter animal was also producing a thick, greenish discharge from the preputial sheath before the onset of electroejaculation. The remaining 6 animals had no visible signs of secretion in the temporal fossa.

\section{Semen evaluation}

Based on the 8 ejaculates containing spermatozoa, the overall mean ( \pm s.e.m.) ejaculate volume was $93.3 \pm 48.4 \mathrm{ml}$ (range $20.3-425 \mathrm{ml}$ ). The mean ejaculate contained $2409 \pm 521 \times 10^{6}$ spermatozoa $/ \mathrm{ml}$ (range $88-4760 \times 10^{6} / \mathrm{ml}$ ). Mean \% sperm motility, status and ejaculate $\mathrm{pH}$ were $70 \cdot 0 \pm 6 \cdot 0,3.9 \pm 0.2$ and $7 \cdot 4 \pm 0 \cdot 1$, respectively. The semen appeared viscous, opaque and white in colour. Of the samples containing spermatozoa, high mean $\%$ motility ratings (range $60-95 \%$ ) were observed, with the exception of one ejaculate which received a $40 \%$ rating. Generally, spermatozoa demonstrated good forward progression, ranging in status from $3 \cdot 0$ to 4.5 .

A high percentage of morphologically normal spermatozoa was present in the ejaculate of each male (mean $77.5 \%$ ). An average of $22.5 \%$ of all spermatozoa exhibited morphological defects including distal cytoplasmic droplets $(11.6 \%)$, bent midpieces $(4.8 \%)$, proximal cytoplasmic droplets $(4 \cdot 5 \%)$, bent flagella $(1 \cdot 5 \%)$ and tightly coiled tails $(0 \cdot 1 \%)$. The majority of bent midpieces $(88.0 \%)$ occurred at the site of a cytoplasmic droplet.

Electroejaculation results tended to vary between collection series (Table 1). A lower proportion of ejaculates and spermic ejaculates were obtained during Series 1 than Series 2 and $3(P<0.05)$. Although a regimented electroejaculation protocol was used, considerable individual variation existed in ejaculate volume within each series. However, mean ejaculate volumes between Series 1 , 2 and 3 were not different $(P>0.05)$. Sperm concentration also did not vary significantly among

Table 1. Ejaculate traits of 9 anaesthetized, electroejaculated African elephants

\begin{tabular}{lccc}
\hline & \multicolumn{3}{c}{ Electroejaculation } \\
\cline { 2 - 4 } & Series 1 & Series 2 & Series 3 \\
\hline Elephants producing seminal fluid & 6 & 9 & 9 \\
Elephants producing spermatozoa & 4 & 7 & 8 \\
Ejaculate volume $(\mathrm{ml})^{*}$ & $32 \cdot 8 \pm 25 \cdot 9$ & $49 \cdot 6 \pm 21 \cdot 9$ & $33 \cdot 6 \pm 17 \cdot 2$ \\
& $(2 \cdot 5-110 \cdot 0)$ & $(10 \cdot 0-175 \cdot 0)$ & $(2 \cdot 0-140 \cdot 0)$ \\
Sperm concentration/ml $\left(\times 10^{6}\right)^{*}$ & $3667 \pm 1200$ & $2322 \pm 814$ & $1638 \pm 417$ \\
Sperm concentration/ejaculate $\left(\times 10^{6}\right)^{*}$ & $(265-5548)$ & $(46-4904)$ & $(1-2904)$ \\
& $(13870-50220)$ & $(7488-197120)$ & $(140-190080)$ \\
Sperm motility $(\%)^{*}$ & $70 \pm 11$ & $60 \pm 9$ & $70 \pm 6$ \\
Sperm status & $(40-95)$ & $(30-95)$ & $(40-95)$ \\
Ejaculate pH* & $3 \cdot 6 \pm 0 \cdot 4$ & $3 \cdot 7 \pm 0 \cdot 2$ & $3 \cdot 9 \pm 0 \cdot 2$ \\
& $(3 \cdot 0-4 \cdot 5)$ & $(3 \cdot 0-4 \cdot 5)$ & $(3 \cdot 0-4 \cdot 5)$ \\
& $6 \cdot 9 \pm 0 \cdot 2$ & $7 \cdot 2 \pm 0 \cdot 2$ & $7 \cdot 7 \pm 0 \cdot 2$ \\
\end{tabular}

* Values are means \pm s.e.m. based on only those ejaculates containing spermatozoa. Ranges are included in parentheses. 
series, but the greatest mean sperm concentration/ml ejaculate was observed in Series 1 with a successive reduction in concentration in Series 2 and Series 3 . The total sperm concentration/ejaculate was 2 -fold greater in Series 2 than in Series 1 or 3 ; however, the wide ranges amongst males prevented this comparison from being significant. Generally, the ejaculates obtained initially were comprised of viscid, gelatinous fluid which became thinner as the electroejaculation protocol progressed. Spermic and aspermic ejaculates demonstrated the gelatinous consistency, therefore no apparent relationship existed between the presence of spermatozoa and viscosity of the ejaculate. Neither percentage sperm motility nor mean sperm status differed amongst the 3 series $(P>0.05)$. Mean ejaculate $\mathrm{pH}$ progressively increased $(P<0.05)$ through the 3 series.

\section{Sperm viability in vitro}

The duration of sperm viability of the raw semen was $<6 \mathrm{~h}$ for each sample, with one exception in which motility was sustained throughout the 6-h assessment interval (Text-fig. 2). This particular sample maintained motility for a total of $14 \mathrm{~h}$. For each ejaculate, sperm motility declined by at least $50 \%$ within $3 \cdot 5 \mathrm{~h}$ of collection.



Text-fig. 2. Duration of sperm motility in vitro at $37^{\circ} \mathrm{C}$ of raw elephant semen $(n=6)$. Individual males are designated by numbers $1-6$. Samples were microscopically evaluated at 30 -min intervals.

\section{Testosterone evaluation}

Marked variation in serum testosterone concentration was detected amongst individual elephants (Text-fig. 3). Testosterone concentrations ranged from 1.4 to $8.2 \mathrm{ng} / \mathrm{ml}$ in the $4 \mathrm{males}$ evaluated in the morning. In 4 of the 5 bulls assessed in the afternoon, testosterone levels were $<0.9$ $\mathrm{ng} / \mathrm{ml}$. The remaining afternoon bull (tests starting at 16:00 h) had very high testosterone concentrations (peak $25.6 \mathrm{ng} / \mathrm{ml}$ ). With the exception of the latter bull, testosterone did not appear to be acutely affected by electroejaculation; testosterone levels in the male with the greatest titres declined over time from $25.6 \mathrm{ng} / \mathrm{ml}$ (before electroejaculation) to $12.2 \mathrm{ng} / \mathrm{ml}$ by $30 \mathrm{~min}$ after electroejaculation. Mean testosterone levels of $0.4 \pm 0 \cdot 1,5 \cdot 3 \pm 0.2$ and $18.3 \pm 1 \cdot 8 \mathrm{ng} / \mathrm{ml}$ were detected, respectively, in the 3 bulls exhibiting temporal gland secretion. Mean testosterone amongst all males was not correlated $(P>0.05)$ with $\%$ sperm motility $(r=0.6)$, status $(r=0.3)$, sperm concentration/ml $(r=-0.5)$ or total sperm concentration/ejaculate $(r=-0 \cdot 2)$. 


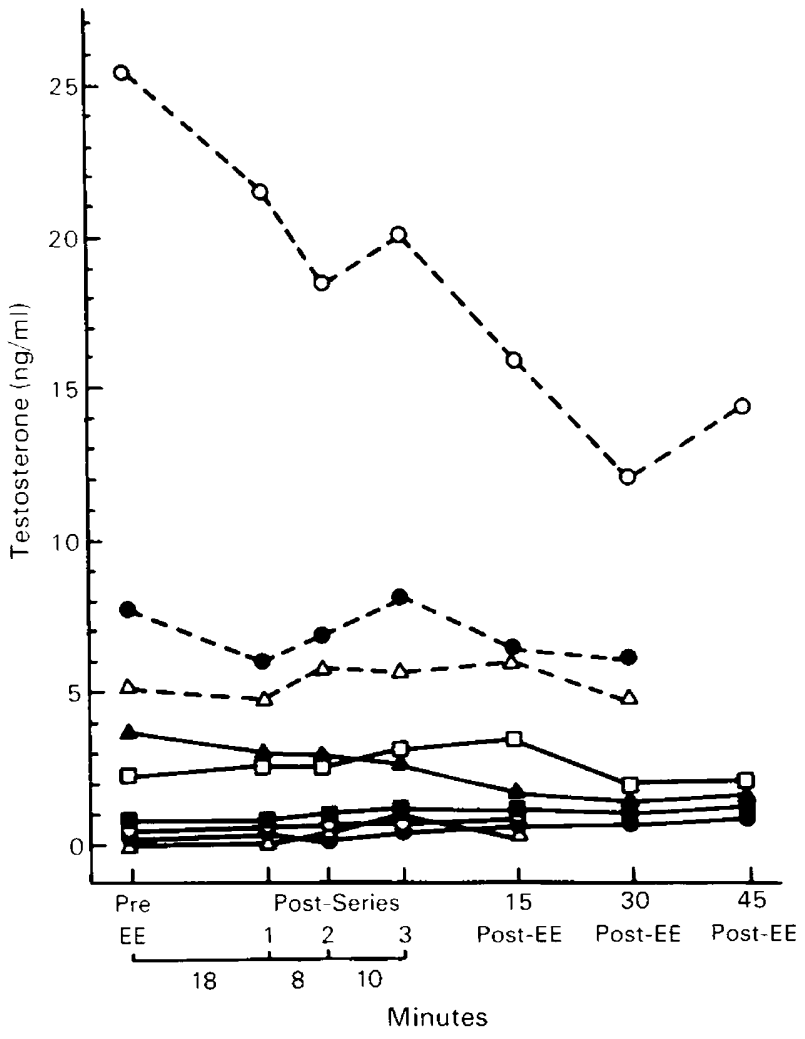

Text-fig. 3. Serum testosterone concentrations in 9 free-ranging African elephants before electroejaculation (Pre-EE), immediately after the 1st, 2nd and 3rd series, and 15, 30 and 45 min after electroejaculation (Post-EE).

\section{Discussion}

The electroejaculation techniques described in the present study were effective and reliable in consistently obtaining ejaculates from wild, free-ranging African elephants. Considerable variation was observed amongst individual males in ejaculate traits. However, high percentages of progressively motile spermatozoa were collected from 8 of 9 elephants. Few pleiomorphic spermatozoa were detected, the most frequent defect being a flagellar cytoplasmic droplet. Similarly, few aberrant sperm forms other than cytoplasmic droplets are noted in rete testes fluid of the African elephant (Jones et al., 1974). The overall mean concentration of spermatozoa observed in the present study $\left(2409 \times 10^{6}\right.$ spermatozoa/ml ejaculate) was considerably greater than that of previous reports concerning electroejaculated African elephants (Jones, 1973: 4.8 $\times 10^{6}$ spermatozoa $/ \mathrm{ml}$; Ruedi, Kupfer, Gutzwiller, Rindisbacher \& Wiesner, 1981: 0.8 × $10^{6}$ spermatozoa $/ \mathrm{ml}$; Ruedi et al., 1983: $196 \times 10^{6} \mathrm{spermatozoa} / \mathrm{ml}$ ) or a masturbated Asian elephant (Jainudeen, Eisenberg \& Jayasinghe, 1971: $1200 \times 10^{6}$ spermatozoa/ml).

The success of the present procedure was presumed to be due to several factors including type and dosage of anaesthetic, probe design and electrostimulation regimen. Previous investigators used a drug combination of etorphine hydrochloride and acepromazine (Immobilon: Reckitt \& Coleman) and occasionally obtained yellowish azoospermic or asthenospermic ejaculates. It is possible that the latter resulted from urine contamination of the semen. To avoid excessive relaxation of the urethral musculature and possible urine contamination during stimulation, a 
tranquillizer such as acepromazine was not administered in our study. Rectal probe design in the present study was similar in terms of length and diameter to those in previous reports (Jones, 1973; Ruedi et al., 1981); however, the individual electrodes of our probe were situated closer, covering only $25 \%$ of the probe circumference (Text-fig. 1). This provided a more condensed area of stimulation of the ventral rectal mucosa over the accessory glands. The intensity of voltage and the number of stimulations applied during electroejaculation also proved to be important criteria. Previous studies employed voltages $<10 \mathrm{~V}$, and Jones et al. (1975) refrained from using $>6 \mathrm{~V}$ because of concern of excessive skeletal muscle stimulation resulting in stiffening of the limbs. In contrast, the present study suggested that voltages ranging from 10 to $30 \mathrm{~V}$ are necessary to elicit ejaculation. Furthermore, it would appear that leg extension can be used as an indicator of proper probe positioning for successful semen collection. Providing electrical stimuli in a repetitious pattern also appeared beneficial in collecting spermatozoa as the greatest proportion of males producing spermic ejaculates occurred during Series 3 . Although sperm concentration $/ \mathrm{ml}$ tended to decline with each series, the maximal mean ejaculate volume occurred in Series 2.

With the exception of 1 ejaculate, elephant spermatozoa generally maintained motility in vitro at $37^{\circ} \mathrm{C}$ for $<6 \mathrm{~h}$. This could be the result of seminal plasma factors and/or the gelatinous viscosity of the ejaculate. In post-mortem studies, Short et al. (1967) noted that the elephant's seminal vesicles produce a watery secretion whereas the bulbo-urethral glands excrete a highly viscous secretion. It is therefore likely that the gelatinous quality of some of the electroejaculates in our study was the result of excessive stimulation of the bulbo-urethral glands. Jones et al. (1975) have reported that buffered saline induces motility of immotile epididymal spermatozoa and the addition of potassium, fructose or both substances further increases motility. Sperm viability of electroejaculates could, therefore, probably be improved by dilution.

Considerable variation is detected in the concentration of intratesticular testosterone in African elephants (Buss \& Johnson, 1967; Short et al., 1967). In general, serum testosterone levels in the present study were comparable to single blood sample concentrations $(0 \cdot 1-6 \cdot 5 \mathrm{ng} / \mathrm{ml})$ collected from culled African elephants (McNeilly, Martin, Hodges \& Smuts, 1983). Usually there was little temporal fluctuation in testosterone levels within individual males over the sampling period. The reason for the marked variation in testosterone amongst males is not precisely known, although the data suggest that diurnal variation in androgen secretion may exist, as in man (Piro, Fraioli, Sciarra \& Conti, 1973) and pig (Ellicott, 1980).

Temporal gland secretion of short duration occurs in immature and mature African elephants of both sexes throughout the year (Perry, 1953) and apparently is not correlated with reproductive activity (Short, 1966; Short et al., 1967). Furthermore, recent evidence indicates that young adult males can be sexually active and mate while showing no signs of temporal gland secretion (Poole, 1982). In the present study, high quality semen was collected from African elephants with various stages of temporal gland activity. The temporal glands were not secreting at the time of electroejaculation in 4 of the bull elephants with the greatest total sperm concentration. This observation also correlated well with reports for the Asian elephant that temporal gland activity and ejaculate quality are independent (Jainudeen et al., 1971). Likewise, season has no apparent influence on reproductive activity in the male. Johnson (1963) and Johnson \& Buss (1967b) first concluded that spermatogenesis in the elephant is not altered after the onset of puberty. Additional studies determined that a well-defined breeding season does not exist in male African elephants (Buss \& Smith, 1966; Laws, 1969; Hanks, 1972) and no seasonal variation is evident in the reproductive hormone concentrations (McNeilly et al., 1983). Therefore, it is presumed that semen could be obtained by electroejaculation from African elephants regardless of season or temporal gland activity.

Unusually high testosterone values ( $>25 \mathrm{ng} / \mathrm{ml}$ ) in 1 animal were similar to levels reported for male Asian elephants during the period of increased aggressive behaviour and temporal gland secretion termed 'musth'. Musth refers to both the physical and behavioural characteristics displayed by males experiencing a heightened period of sexual activity (Poole, Kasman, Ramsay \& 
Lasley, 1984). In Asian elephants, marked increases in plasma testosterone have been detected in males under transition from non-musth $(<4 \cdot 3 \mathrm{ng} / \mathrm{ml})$ to musth $(13.7-65.4 \mathrm{ng} / \mathrm{ml})$ periods (Jainudeen, Katongole \& Short, 1972). Musth has been observed in free-ranging African elephants demonstrating pronounced enlargement of and continuous and copious secretions from the temporal glands, increased aggression, urine dripping and greenish discharge of the penis and penile sheath (Poole \& Moss, 1981). Furthermore, urinary testosterone concentrations from single urine samples are greater in males that are in or around the time of behavioural musth (Poole et al., 1984). In the present study, temporal gland secretion was observed in 2 males with moderate or low serum testosterone levels. However, the bull demonstrating the greatest testosterone titres also displayed, before electroejaculation, a greenish preputial discharge and extensive temporal gland secretion, suggesting that this free-ranging male might have been experiencing musth.

We thank the National Parks Board of the Republic of South Africa and Dr U. de V. Pienaar for support and co-operation, and the staff of Kruger National Park for their generous help and hospitality. This research was supported by the Friends of the National Zoological Park (FONZ), Washington, D.C., and in part, by a grant from the Charles Ulrich and Josephine Bay Foundation, administered by the American Association of Zoo Veterinarians. J.G.H. is partly supported by a grant from the Womens' Committee of the Smithsonian Associates, the Smithsonian Institution, Washington, D.C.

\section{References}

Buss, 1.O. \& Johnson, Q.W. (1967) Relationship of Leydig cell characteristics and intratesticular testosterone levels to sexual activity in the African elephant. Anat. Rec. 157, 191-196.

Buss, 1.O. \& Smith, N.S. (1966) Observations on reproduction and breeding behavior of the African elephant. J. Wildl. Mgmt 30, 375-388.

Ellicott, A.R. (1980) Hormonal profiles in the pig. In Current Therapy in Theriogenology, pp. 1011-1013. Ed. D. A. Morrow. W. B. Saunders Co., Philadelphia.

Hanks, J. (1972) Reproduction of elephant, Loxodonta africana, in the Luangwa Valley, Zambia. $J$. Reprod. Fert. 30, 13-26.

Holt, W.V., Jones, R.C. \& Skinner, J.D. (1980) Studies on the deferent ducts from the testis of the African elephant, Loxodonta africana. II. Histochemistry of the epididymis. $J$. Anat. 130, 367-379.

Howard, J.G., Pursel, V.G., Wildt, D.E. \& Bush, M. (1981) Comparison of various extenders for freezepreservation of semen from selective captive wild ungulates. J. Am. Vet. Med. Assoc. 179, 1157-1161.

Howard, J.G., Wildt, D.E., Chakraborty, P.K. \& Bush, M. (1983) Reproductive traits including seasonal observations on sperm quality and serum hormone concentrations in the Dorcas gazelle. Theriogenology 20, 221-234.

Jainudeen, M.R., Eisenberg, J.F. \& Jayasinghe, J.B. (1971) Semen of the Ceylon elephant, Elephas maximus. J. Reprod. Fert. 24, 213-217.

Jainudeen, M.R., Katongole, C.B. \& Short, R.V. (1972) Plasma testosterone in relation to musth and sexual activity in the male Asiatic elephant, Elephas maximus. J. Reprod. Fert. 29, 99-103.

Johnson, O.W. (1963) Histological and quantitative char- acteristics of the testes, observations on the teeth and pituitary gland, and the possibility of reproductive cyclicity in the African elephant (Loxodonta africana). Ph.D. thesis, Washington State University.

Johnson, O.W. \& Buss. I.O. (1967a) The testis of the African elephant (Loxodonta africana). I. Histological features. J. Reprod. Fert. 13, 11-21.

Johnson, O.W. \& Buss, I.O. (1967b) The testis of the African elephant (Loxodonta africana). II. Development, puberty and weight. J. Reprod. Fert. 13, 23-30.

Jones, R.C. (1973) Collection, motility and storage of spermatozoa from the African elephant, Loxodonta africana. Nature, Lond. 243, 38-39.

Jones, R.C. (1978) Studies on handling spermatozoa from the African elephant, Loxodonta africana. Symp. zool. Soc. Lond. 43, 261-269.

Jones, R.C. (1980) Luminal composition and maturation of spermatozoa in the genital ducts of the African elephant (Loxodonta africana). J. Reprod. Fert. 60, 87-93.

Jones, R.C. \& Brosnan, M.F. (1981) Studies of the deferent ducts from the testis of the African elephant, Loxodonta africana. I. Structural differentiation. $J$. Anat. 132, 371-386.

Jones, R.C., Rowlands, I.W. \& Skinner, J.D. (1974) Spermatozoa in the genital ducts of the African elephant, Loxodonta africana. J. Reprod. Fert. 41, 189192.

Jones, R.C., Bailey, D.W. \& Skinner, J.D. (1975) Studies on the collection and storage of semen from the African elephant, Loxodonta africana. Koedoe 18, 147-164.

Laws, R.M. (1969) Aspects of reproduction in the African elephant, Loxodonta africana. J. Reprod. Fert., Suppl. 6, 193-217. 
McNeilly, A.S., Martin, R.D., Hodges, J.K. \& Smuts, G. L. (1983) Blood concentrations of gonadotrophins, prolactin and gonadal steroids in males and in nonpregnant and pregnant female African elephants (Loxodonta africana). J. Reprod. Fert. 67, 113-120.

Perry, J.S. (1953) The reproduction of the African elephant, Loxodonta africana. Phil. Trans. R. Soc. B 237, 93-149.

Piro, C., Fraioli, F., Sciarra, F. \& Conti, C. (1973) Circadian rhythm of plasma testosterone, cortisol and gonadotropins in normal male subjects. J. Steroid Biochem. 4, 321-329.

Poole, J.H. (1982) Musth and male-male competition in the African elephant. Ph.D. thesis, University of Cambridge.

Poole, J.H. \& Moss, C.J. (1981) Musth in the African elephant, Loxodonta africana. Nature, Lond. 292, $830-831$.

Poole, J.H., Kasman, L.H., Ramsay, E.C. \& Lasley, B.L. (1984) Musth and urinary testosterone concentrations in the African elephant (Loxodonta africana). $J$. Reprod. Fert. 70, 255-260.

Ruedi, V.D. \& Kupfer, U. (1981) Semen collection in the African elephant (Loxodonta africana): a step towards artificial insemination. Proc. Am. Ass. Zoo Vet., pp. 142-143.
Ruedi, V.D., Kupfer, U., Gutzwiller, A., Rindisbacher, F. \& Wiesner, H. (1981) Collection of semen from African elephant (Loxodonta africana). Planning of artificial insemination. Proc. 13th Int. Symp. Dis. Zoo Anim., pp. 349-351.

Ruedi, V.D., Kupfer, U., Girard, J. \& Gutzwiller, A. (1983) Studies into reproductive physiology of African elephant (Loxodonta africana). Collection of semen from wild bulls. Proc. 25th Int. Symp. Dis. Zoo Anim., pp. 341-348.

Short, R.V. (1966) Oestrous behaviour, ovulation and the formation of the corpus luteum in the African elephant, Loxodonta africana. E. Afr. Wildl. J. 4, 5668.

Short, R.V., Mann, T. \& Hay, M.F. (1967) Male reproductive organs of the African elephant, Loxodonta africana. J. Reprod. Fert. 13, 517-536.

Steel, R.G.D. \& Torrie, J.H. (1960) Principles and Procedures of Statistics. McGraw-Hill, New York.

Wildt, D.E., Bush, M., Howard, J.G., O'Brien, S.J., Meltzer, D., van Dyk, A., Ebedes, H. \& Brand, D.J. (1983) Unique seminal quality in the South African cheetah and a comparative evaluation in the domestic cat. Biol. Reprod. 29, 1019-1025.

Received 31 January 1984 